TAO, Vol. 15, No. 3, 413-435, September 2004

\title{
Ionospheric Precursors of Earthquakes; Recent Advances in Theory and Practical Applications
}

\author{
Sergey Pulinets, ${ }^{1, *}$
}

(Manuscript received 8 March 2004, in final form 15 June 2004)

\begin{abstract}
This paper accumulates the recent advances in scientific understanding of the problem of seismo-ionospheric coupling. Present research focuses on three main areas: the physical mechanism, main phenomenological features of ionospheric variations associated with earthquakes, and their statistical properties permitting use of them in practical applications. In this paper, the developed physical model bridges the traditional precursors of earthquakes and ionospheric ones, demonstrating that the latter belong to the same family. In this regard the earthquake preparation zone is key generating the scaling law and the relationship between geochemical precursors, anomalous electric field involved in ionospheric variations initiated, and the ionospheric irregularities themselves. Revealed ionospheric precursor phenomena and their statistical parameters are used to develop a pattern recognition technique and other statistical processing techniques that can be used in short-term earthquake prediction. Finally a possible system of ground based measurements and satellite monitoring is proposed for regional and global monitoring and possible short-term prediction of destructive earthquakes.
\end{abstract}

(Key words: Ionospheric precursors)

\section{INTRODUCTION}

The history of seismo-ionospheric coupling studies has passed through several stages starting from astonishment after initial discovery, enthusiastic but often speculative publications, and defeat by severe critics, to ultimately consecutive and systematic studies which have led to a substantiated physical model. It is commonly accepted that the Good Friday Alaska earth-

\footnotetext{
${ }^{1}$ Institute of Geophysics, National Autonomous University of Mexico, Mexico D.F., Mexico

* Corresponding author address: Prof. Sergey Pulinets, Institute of Geophysics, UNAM, Ciudad

Universitaria, Delegacion Coyoacan, 04510, Mexico D.F.,Mexico; E-mail: pulse@geofisica.unam.mx
} 
quake on March 27 of 1964 gave seismo-ionospheric coupling studies its initial impetus. Among many publications describing the electromagnetic and ionospheric phenomena associated with this earthquake, one can find at least two, where pre-earthquake effects were mentioned (Moore 1964; Davies and Baker 1965). The first publications dealing with ionospheric parameter variations as seismic precursors were Antselevich (1971) study of the variations of $f o E$ parameter before the Tashkent earthquake 1966, and the Datchenko et al. (1972) study of ionosphere electron variations before the same Tashkent quake. Consequently, case study papers started to appear regularly. These were based mainly on ground-based ionosondes data; however, the first papers using satellite data began to appear as well (Gokhberg et al. 1983). The first-year papers dealing with seismo-ionospheric precursory phenomena were characterized by a mainly phenomenological approach without a solid physical background. However, over the ensuing years use of different processing techniques, has led to the accumulation of a substantial credible knowledge base. This long history of seismo-ionospheric coupling studies can be found in the following reviews: Liperovsky et al. (1990); Gaivoronskaya (1991); Liperovsky et al. (1992); Parrot et al. (1993); Pulinets et al. (1994); Gokhberg et al. (1995).

Concerning the physical explanation, two main hypotheses (with some modifications or options) have competed to describe these phenomena. The first of these was the influence of acoustic gravity waves generated in the earthquake zone on the ionosphere, and the second was anomalous vertical electric fields penetrating from the earthquake zone into the ionosphere. We can consider conductivity changes in the air as an option in the electric field model. Initially, the acoustic hypothesis led studies in this area. Mareev et al. (2002) is a recent publication demonstrating the idea of gravity wave generation by pre-seismic activity of emanating gases. This idea, however, is yet to receive strong experimental support. Up until now the registered experimentally ionospheric disturbances stimulated by even strong ground movements after intensive earthquakes has been very small. Calais and Minster (1998) who used GPS TEC techniques to experimentally measure the ionospheric effect from the Northridge earthquake of 17 January 1994, $M=6.7$ detected that the TEC variations associated with AGW were 2 - 2.5 orders of magnitude lower than the background ionospheric variations. These experimental results of Calais and Minster (1998) are supported by theoretical estimations of Davies and Archambeau (1998). The authors of the paper solve in the most accurate (to date) form, including nonlinear effects, the problem of excitation of ionospheric perturbations by acoustic gravity waves generated by shallow earthquakes. Most would agree that an earthquake itself generates much more intense air oscillations than any possible precursory phenomena. Calculations by Davies and Archambeau (1998) show that the relative change in electron concentration in the maximum phase reaches at least $0.3 \%$ which is two orders of magnitude lower than the ordinary value of the day-to-day ionosphere variability and practically undetectable. The most recent support of this idea are the latest results of the ionosphere oscillations registered by the GPS network after the extremely strong Denali Park Alaska Earthquake of 03 November 2002 - Magnitude 7.9 (Ducic et al. 2003). However, these show a very small ionosphere modification even after oscillation of huge areas with a magnitude several orders larger than the possible disturbance created by the pre-earthquake gases release. In any case, the acoustic hypothesis cannot explain the observed experimentally very strong variations of TEC before strong earthquakes (Liu et al. 2004). All results and calculations mentioned above allow us to 
believe that the acoustic hypothesis may be forgotten forever. Hence, in the following discussion we will stay within the framework of the electric field hypothesis. The paper is constructed in the following way. The physical model is discussed first, than the experimental results (with accent on the recently obtained) will be interpreted based on the presented physical model, and then practical applications will be discussed, including satellite technologies.

\section{THE PHYSICAL MODEL OF SEISMO-IONOSPHERIC COUPLING}

\subsection{Near Ground Processes}

All the processes involved in the physical mechanism of seismo-ionospheric coupling are schematically presented in Fig. 1. In the area of earthquake preparation (the size of which is determined by the magnitude of future earthquakes, Pulinets et al. 2004a) besides mechanical transformations, active geochemical processes take place, including radon emanation and several types of gaseous components such as noble and greenhouse gases. The preparatory stage for ionospheric precursor initiation is formation of the near ground plasma in the form of long living ion clusters which are the result of ion-molecular reactions (after ionization by radon) in the near ground layer of the atmosphere and water molecule attachment to the finally formed ions. Just the water molecules high dipole moment prevents the newly formed ion clusters from recombination. Pulinets and Boyarchuk (2004) give a detailed description of the process of ion cluster formation in the near ground layer. Due to Coulomb attraction of positive and negative ion clusters, quasi-neutral clusters are formed. In the dusty plasma theory this process is called coagulation (Horanyi and Goertz 1990; Kikuchi 2001). The formation of neutral clusters is a final step in the preparatory stage such that eventually we have the near ground layer of atmosphere in the earthquake preparation area rich with latent ions masked by the formed neutral clusters (Pulinets et al. 2002a).

The second stage is the generation of the anomalous electric field. It is known that before an earthquake intensive gas discharges occur from the crust (mainly $\mathrm{CO}_{2}$ ) in the earthquake preparation zone (Voitov and Dobrovolsky 1994). These gas releases play a twofold role. By generating air motion they create instabilities able to stimulate acoustic gravity wave generation. These intensive air movements destroy neutral clusters because of weakness in the Coulomb interaction. As a result within a short time the near ground layer of atmosphere becomes rich in ions (the estimated concentration is $10^{5}-10^{6} \mathrm{~cm}^{-3}$ ). The charge separation process described in Pulinets et al. (2000) leads to generation of an anomalously strong vertical electric field in comparison with the fair weather electric field $\left(\sim 1 \mathrm{kV} \mathrm{m}^{-1}\right.$ and $\sim 100 \mathrm{~V} \mathrm{~m}^{-1}$, respectively). One of the main factors for the charge separation is the different mobility of positive and negative ions - components of the atmospheric plasma. One can find a lot of possibilities for electrization of such plasma media in Kikuchi (2001). Anomalous electric field generation is the final stage of the first act in the seismo-ionospheric coupling chain of the processes within the troposphere-upper atmosphere - ionosphere. It should be noted that under different geophysical conditions (for example the presence of mist) the anomalous electric field may have as direction downward (coinciding with the natural direction of atmo- 


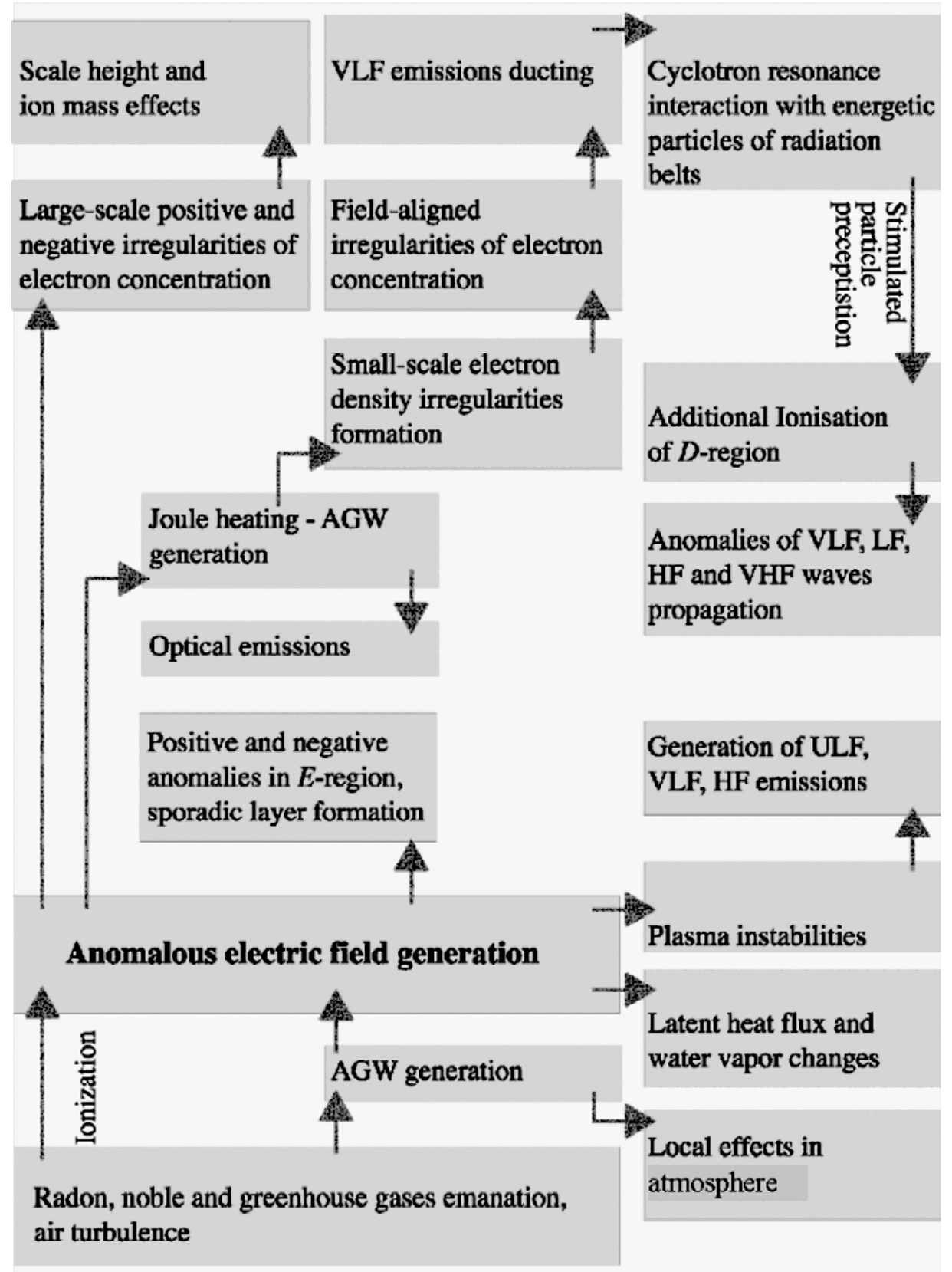

Fig. 1. Block diagram of seismo-ionospheric coupling model. 
spheric electric field), so upward. Cases of the seismogenic electric field generation before strong earthquakes are well documented. See: Jianguo (1989); Nikiforova and Michnovski (1995); Vershinin et al. (1999); Hao et al. (2000); Rulenko (2000).

Additional discussion concerning the near ground processes is needed before discussing ionospheric modifications due to any anomalous electric field. Firstly, underground gas discharges, in addition to their destructive role regarding neutral clusters, may also carry with them submicron aerosols, which, it is well known, will increase the intensity of an electric field due to the drop in air conductivity created by aerosols (Krider and Roble 1986). A calculation of electric field growth due to additional aerosol flux can be found in Pulinets et al (2000). The second point relates to seismo-electromagnetic emissions in ULF, ELF and VLF bands registered in seismically active zones before earthquakes (Nagao et al. 2002). Their detection and identification (separate from thunderstorm induced emissions and technogenic emissions) is now well developed. At least two techniques are used: direction finding (Ismaguilov et al. 2001), and polarization techniques (Hattori et al. 2002); however, the physical nature of the observed emissions still remains unclear. In our model we hypothesize a possible way of explaining these emissions. One can see from our discussion above that the near ground layer of atmosphere becomes real plasma with particle concentration comparable with some regions of the Earth's ionosphere. In addition, this plasma is posed in a strong electric field, where one should expect particle acceleration and excitation of plasma instabilities. An estimation of the plasma frequency for the cluster ion $\mathrm{NO}_{3}{ }^{-} \cdot\left(\mathrm{H}_{2} \mathrm{O}\right)_{\mathrm{n}}$, where $n$ is the number of water molecules in the cluster, is given here. When $n=6$ the atomic mass will be $M=190$ a.e. which is equivalent to $m=3.15 \cdot 10^{-22} \mathrm{~g}$ and with the concentration of charged particles of the order $10^{6} \mathrm{~cm}^{-3}$ this gives $f_{p}=\omega_{p} / 2 \pi \approx 16.9 \mathrm{kHz}$ which lies just inside the VLF frequency band. Taking into account that plasma concentration, and ion cluster mass may change considerably; one may expect the coverage of the whole ULF-ELF-VLF band. Here, the thermal plasma noise on the local plasma frequency can be essentially increased by the processes of electric field generation and particle acceleration. Other possible candidates for instability involving particle movement are Cerenkov and Bremstrallung emissions. The set of plasma instabilities that can be stimulated in the dusty plasma can be found in Kikuchi (2001). Ion waves and dust acoustic waves are also possible candidates. The VLF emission excitation by possible coronal discharge from spikes and cutting edges in presence of the anomalous electric field is proposed by Bardakov et al. (2004).

\subsection{Anomalous Electric Field Effects in the Ionosphere}

Anomalous electric field penetrating into the $E$-region of the ionosphere creates irregularities registered experimentally (Liperovsky et al. 2000). Depending on the direction of the electric field on the ground surface (i.e., up or down), negative or positive deviations in the electron concentration may be created, respectively (Pulinets et al. 1998). In addition, the shape of the area generating the electric field, i.e., circular or elongated, determines the shape of the irregularity within the ionosphere. However, in all cases it is only the perpendicular component, to the geomagnetic field lines, of the anomalous electric field that penetrates into the ionosphere. In cases where the anomalous electric field is directed down to the ground 
surface, a sporadic E-layer will be formed in the ionosphere over the area of earthquake preparation. This has been tested experimentally by Ondoh and Hayakawa (1999) and theoretically considered by Kim et al. (1994) as well.

Due to equipotentiality of geomagnetic field lines the electric field practically without any decay penetrates at the higher levels of the ionosphere. In the $F$-region two main effects should be noted. In the area of maximal conductivity due to Joule heating acoustic gravity waves will be generated giving rise to the small-scale density irregularities within the ionosphere (Hegai et al. 1997). These processes are manifested in periodic electron density oscillations registered at different ionospheric heights by radiophysical techniques and optical monitoring of the ionosphere and are well supported by the experimental data (Chmyrev et al. 1997). The other, probably main and well-documented effect is formation of the large-scale irregularities of electron concentrations in the $F 2$ region of the ionosphere (Pulinets and Legen'ka 2003). They were registered by satellite, and from the ground by the ground based ionosondes and ground network of GPS receivers (Liu et al. 2004). Due to the complex character of particle drift in the $F$-region in crossed electric and geomagnetic fields, large scale anomalies in the $F$-region, as well as anomalies connected with AGW propagation may be registered not just over the impending earthquake epicenter, but also shifting in an equatorward direction. One should keep this in mind in practical applications.

\subsection{Effects in the Magnetosphere}

At higher levels one can expect the following effects. Small-scale irregularities spread along the geomagnetic field lines into the magnetosphere creating field aligned ducts where VLF emissions of different origin will be scattered (Kim and Hegai 1997; Sorokin et al. 2000; McCormick et al. 2002). This will lead to increased levels of VLF emission within the magnetic tubes along the areas of anomalous electric field generation (Shklyar and Nagano 1998). Just this VLF emission amplification within the modified magnetospheric tube was originally registered by satellites in the early years of electromagnetic precursor satellite studies. Due to plasma drift processes the shape of the modified area at magnetospheric heights will not be exactly the same as that on the earth surface, but elongated in the zonal direction proportionally at approximately 1:3 for the meridional and longitudinal sizes of the modified volume of the magnetosphere (Larkina et al. 1989; Kim and Hegai 1997). As a result of the cyclotron interaction of VLF emissions with radiation belt particles their stimulated precipitation starts. The precipitating particles associated with earthquake preparation were also registered on many satellites (Galper et al. 1995).

\subsection{Effects in D-region of the Ionosphere}

Finally the complex chain of processes in the atmosphere, ionosphere, and magnetosphere results in precipitating particles producing ionization of the lower ionosphere. The ionization leads to an increase in the electron concentration in the $D$-region of the ionosphere which is equivalent to lowering the ionosphere (Kim et al. 2002). This lowering changes the condition of radio wave propagation in different frequency bands from VLF up to VHF. Anoma- 
lous effects of radio waves propagation before strong earthquakes have been registered experimentally (Gufeld et al. 1992, Biagi et al. 2001, Kushida and Kushida 2002).

\section{THE THERMAL ANOMALIES AND PROBLEM OF LATENT HEAT}

One of the rapidly developing areas in earthquake precursors studies is the investigation of ground surface thermal anomalies (Tramutoli et al. 2001; Tronin et al. 2002) which appear several days before strong earthquakes in the earthquake preparation area. The thermal anomalies development time scale is very similar to the timescale of ionospheric precursors. Many speculations on the possible physical mechanism responsible for thermal anomalies exist from heat released by stress in the earth crust to underground water convection. However, underground processes cannot explain observed changes in not only the surface temperature, but also other atmospheric parameters, for example, humidity (Tronin 2002). The troposphere in a thermodynamic equilibrium is a complex system of interrelated atmospheric parameters including atmospheric pressure, temperature and humidity. A change in one of these parameters immediately leads to a change in the others. In addition, another parameter involved in these changes is latent heat which is closely related with water content in the air and processes of water evaporation. So it is natural that after the discovery of pre-earthquake thermal anomalies, latent heat anomalies were also discovered with the help of remote sensing techniques (Dey and Singh 2003). Dey and Singh (2003) presented data for 40 strong earthquakes where anomalous variations in surface latent heat flux were registered. They demonstrated that the anomalous surface latent heat increase takes place within a time interval several days before a strong earthquake in the earthquake preparation zone. To address this point, we should return to the seismo-ionosphere coupling model presented above. As it was shown, water molecules attachment (and detachment) processes can significantly change the partial pressure of water vapor in the air reflecting on the value of the total atmospheric pressure. The same process that changes the water vapor content in a free state changes the air humidity and the amount of the heat necessary for water evaporation i.e., latent heat flux. According to Sedunov et al. (1997) water molecule transition from free state to attached (and reverse) consumes or releases $\sim 800$ - $900 \mathrm{cal} \mathrm{g}^{-1}$ of energy. This means that plasmachemical reactions under action of the ionization considered in paragraph 2.1 may contribute considerably to the thermal balance over the area of earthquake preparation.

Another effect that may contribute to changes in water evaporation over the earthquake preparation zone is related to the strong electric field action on water evaporation properties. Krasikov (2001) in his experiments detected a difference in the evaporation velocity in the different directions of a strong electric field imposed on the evaporation camera. It is shown in Fig. 2. The evaporation velocity was larger when the electric field was directed down rather. So that changes in an anomalous electric field's direction observed experimentally (Nikiforova and Michnowski 1995; Vershinin et al. 1999) may also contribute to the thermal balance in seismically active areas.

From the discussion above one can conclude that at least two processes can essentially change the thermodynamics of the lower atmospheric layers. They are the action of the ioniza- 
tion source and strong electric fields, and that these processes are the most probable sources of observed thermal and surface latent heat flux anomalies before strong earthquakes. The recent theoretical calculations of the evaporation velocity under action of ionization source show essential effect in relative air humidity supporting the collected experimental data (Pulinets et al. 2004d).

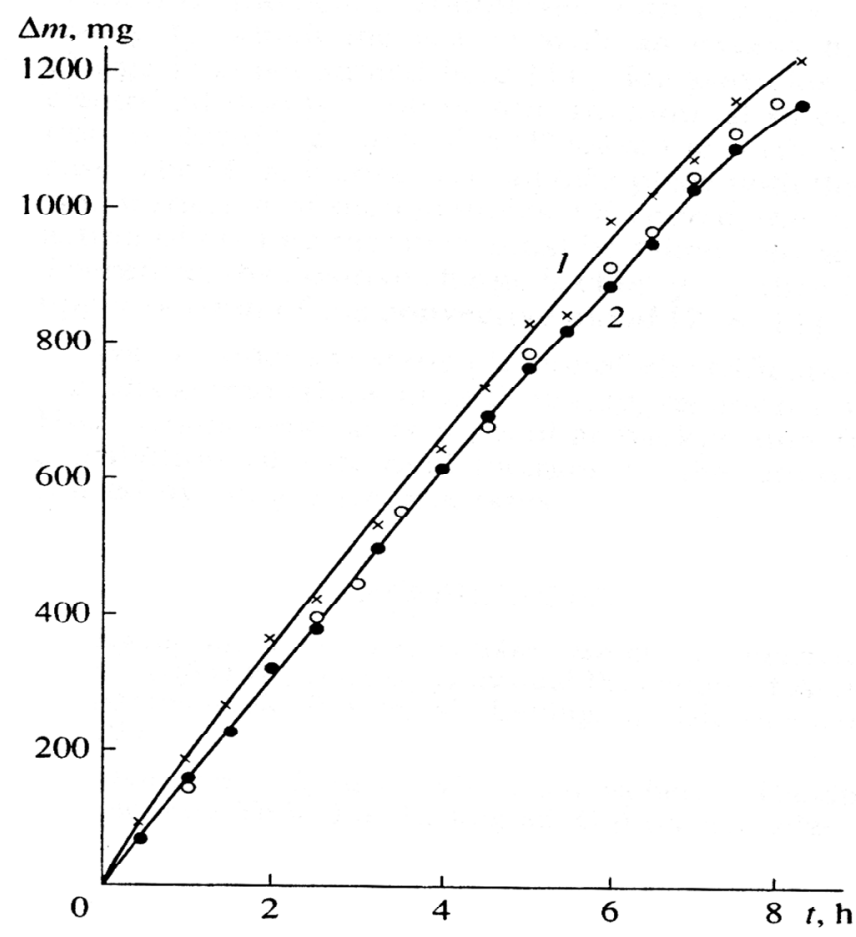

Fig. 2. Dependence of the water mass change under evaporation for electric field directed down (+), for electric field directed up (open circles), without electric field (closed circles).

\section{EARTHQUAKE PREPARATION AREA CONCEPTION}

Studies of Soviet researchers at the Garm testing range (Tajikistan) in the $1970^{\text {th }}-1980^{\text {th }}$, as well as the studies of western scientists, indicated that changes in the Earth's crust in the form of deformations, variations in seismic waves velocity, emanation of gases from the Earth's crust, changes in crustal electric conductivity, etc. are observed not only at the earthquake source but also in the zone exceeding the source dimensions by an order of magnitude. This made it possible to develop a dilatation theory - deformation of the Earth's crust, fracturing, 
and formation of a main fault in the so-called earthquake preparation zone (Scholz et al. 1973; Mjachkin et al. 1975). The dimensions of this zone were estimated by Dobrovolsky et al. (1979), based on calculating the Earth's crust elastic deformation at a level of $10^{-8}$, and can be presented in the form:

$$
\rho=10^{0.43 M} \mathrm{~km},
$$

where $\rho$ is the radius of the earthquake preparation zone, and $M$ is the magnitude. The values of the earthquake preparation zone radius in accordance with formula (1) are shown in Table 1.

Table 1. The values of the earthquake preparation zone radius versus magnitude in accordance with formula (1)

\begin{tabular}{llllllll}
\hline Magnitude & 3 & 4 & 5 & 6 & 7 & 8 & 9 \\
\hline $\begin{array}{l}\text { Earthquake preparation } \\
\text { zone radius } \rho(\mathrm{km})\end{array}$ & 19.5 & 52.5 & 141 & 380 & 1022 & 2754 & 7413 \\
\hline
\end{tabular}

Calculation results for the Earth's crust mechanical deformation for the case of threedimensional inclusion with regard to the source depth are given in (Dobrovolsky et al. 1989). In this case the preparation zone is estimated as:

$$
a=10^{0.414 M-1.696} \mathrm{~km},
$$

where $a$ is the deformation zone radius. Although a dilatation theory is valid only for shallow earthquakes, and prognostic papers now are based on the statistical processing of seismic data, the use chaos theory and self-organized criticality (Kossobokov et al. 2000), the dimensions of the preparation zone determined statistically by modern theories are of the same order of magnitude as older determinations of Dobrovolsky et al. (1979).

The validity of the Dobrovolsky's formula for estimating the size of a modified area in the ionosphere before earthquakes, used in Pulinets et al., (2000) and Pulinets et al. (2002a) should be discussed. Radon is one of the geophysical precursors of earthquakes determined in the papers based on the physical background of earthquake prediction (Scholz et al. 1973). At the same time radon is one of the main components of the physical mechanism of seismogenic electric field generation. It means that the area occupied by the anomalous fluxes of radon should be of the same order of magnitude as areas occupied by the seismogenic electric field. Consequently, the answer to be looked for in the literature describing geochemical effects before earthquakes. In a critical review by Toutain and Baurbon (1998), listing more than 150 publications of different authors on measurements of geochemical earthquake precursors, estimation of the zone where geochemical precursors (including radon) were observed as a function of magnitude (Fig. 3b) concluded that the zone of geochemical precursors is completely identical to the zone calculated by Dobrovolsky (Fig. 3a). Moreover, Fleischer (1981), in his 
studies based on an analysis of geochemical data, obtained his own dependence of the zone with observed geochemical precursors on magnitude (Fig. 3b), which almost completely coincides with the curve obtained by Dobrovolsky. Thus, we can state that the zone occupied by the anomalous electric field, computed in the model (Pulinets et al. 2000), can be estimated from formula (1). Hence, it becomes clear that the appearance of a magnitude threshold $(M \sim 5)$ can be used to detect ionospheric earthquake precursors. According to calculations (Pulinets et al. 2000), an anomalous electric field can effectively penetrate into the ionosphere, when the size of the zone where seismogenic field is present, is no less than $200 \mathrm{~km}$, which corresponds to a magnitude of $M=4.65$ according to (1). Taking into account that it is a minimal estimate,

(a)

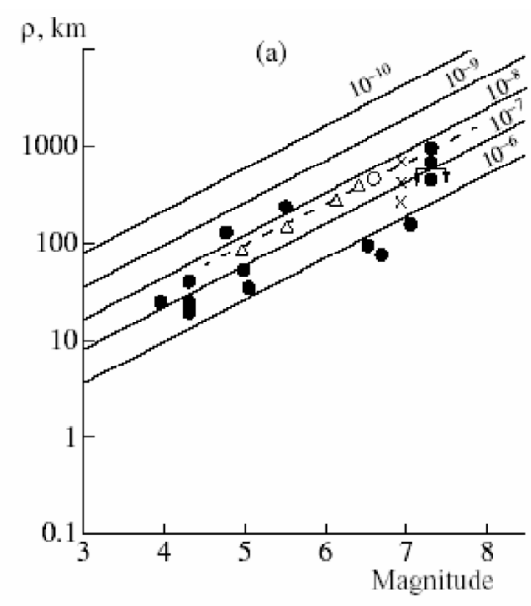

(b)

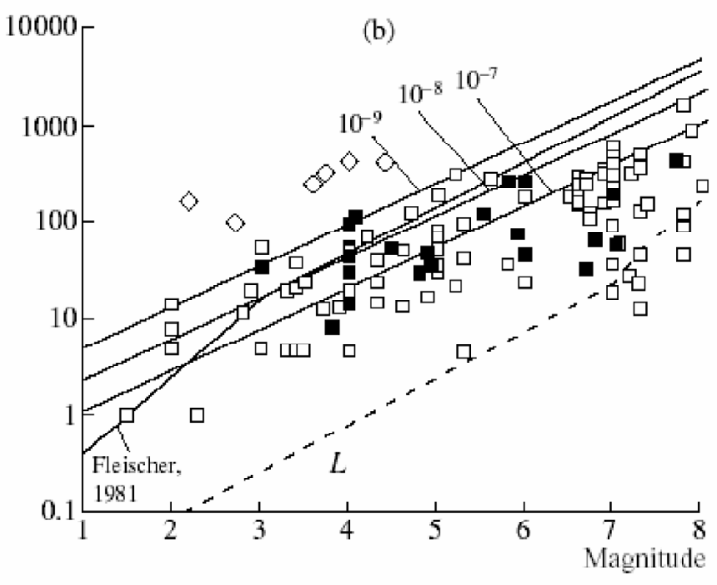

Fig. 3. (a) The distance from the precursor to the epicenter as a function of the earthquake magnitude. Geochemical precursors are denoted by filled circles; the resistance from different sources, by dashes and crosses; telluric currents, by triangles; radon, by arrows; and light effects, by open circles. (b) The distance from the precursor to the epicenter as a function of the earthquake magnitude for geochemical data [12]. Opened and filled squares denote measurements of radon and other gaseous anomalies, respectively. Continuous thin lines show the relation between the deformation radius and magnitude for deformations of $10^{-7}$, to $10^{-9}$ in accordance with the empirical equation of Dobrovolsky et al. (1979). Thick line represents the empirical dependence derived by Fleischer (1981) as a result of calibrating the maximal distance between the measured anomaly and epicenter for a given magnitude on the basis of the shear dislocations law for earthquakes. The dashed line shows the typical size of the rupture zone of an active fault as a function of magnitude in accordance with the empirical equation of Aki and Richards (1980). 
a threshold of $M \sim 5$ seems quite reasonable and corresponds to experimental observations.

One can conclude that three completely different physical manifestations of earthquake preparation such as mechanical deformation, geochemical emanations from the crust and ionospheric phenomena have the same order in terms of spatial scale and dependence on a future earthquake magnitude. This means they are different aspects of a common process and that ionospheric precursors are not some exotic kind of phenomena but are closely connected with all the physical and chemical processes taking place during earthquake preparation. So one can consider ionospheric precursors of earthquakes as a member of the family of usual geophysical precursors described in many publications (Scholz et al. 1973), which have a similar spatial and temporal scale. The same thing can be said of other electromagnetic precursors to earthquakes because all of them can be explained within the framework of the presented model of seismo-ionospheric coupling. Seismoelectromagnetic phenomena are simply the some parts of a complex chain of processes connected one to another. We can conclude then that there is no separate electromagnetic precursor direction, ionospheric precursor direction, geophysical precursor direction etc., all are short-term earthquake precursors and should be regarded by seismologists as one family.

\section{THE HIERARCHY OF ELECTROMAGNETIC AND IONOSPHERIC PRECURSORS}

From the discussion above one can embattle all electromagnetic precursors mentioned in the literature. If registered ground level ULF-ELF noises are a result of plasma instabilities in atmospheric plasma, their intensity should be closely related with radon emanations. It is probably worth checking existing records of seismo-electromagnetic emissions, with radon records in corresponding areas. Recent results of common measurements of radon and ULF emissions with the help of magnetometers in Israel give strong support to this idea (Zafrir et al. 2003). From this perspective we should regard the geochemical processes in the near ground layer of the atmosphere as primary in relation to observed electromagnetic phenomena.

Next by order in hierarchy should be the vertical atmospheric electric field variations. They appear at the final stage of earthquake development when atmospheric plasma has undergone preparatory changes. It is unnecessary to have very strong fields up to several kilovolts per meter; however, clear deviations from the Carnegie curve under fair weather conditions should have been registered.

Then VLF-HF-VHF emissions, which are the result of the processes in aerosol layers forming over the area of strong electric fields and described in Pulinets et al. (2002a) and Pulinets and Boyarchuk (2004) should be considered.

Finally, ionospheric anomalies will appear including small scale and large scale irregularities, optical emissions, and light ions anomalies, and then effects in the plasmasphere and magnetosphere such as particle precipitation, and anomalous VLF emissions should be registered in ionosphere and plasmasphere.

Anomalies in VLF signal propagation are the ultimate member in this turn, because they are the result of D-region modification after particle precipitation from the magnetosphere. 
Thermal anomalies and latent heat flux anomalies will appear after gas discharges and abrupt changes in the atmospheric plasma accompanied by thermodynamic changes in air temperature, humidity and pressure involving water molecule attachment-detachment transitions. Usually these are associated with ionospheric anomalies as was registered before the Colima earthquake of 21.01.2003 ( 7.8) in Mexico (Pulinets et al. 2004d). An anomalous increase in the surface latent heat flux was registered on 18 of January (Day and Singh 2003) together with an ionospheric anomaly registered by GPS TEC measurements. Results of these records are shown in the Fig. 4. These latest experimental results present solid support to the physical model of seismo-ionospheric coupling described above.

\section{PECULIARITIES IN THE DIFFERENT TECHNIQUES REQUIRED FOR IONOSPHERIC PRECURSOR REGISTRATION}

All three techniques used for ionosphere monitoring: vertical sounding, topside vertical sounding and GPS TEC reveal similar properties in ionospheric precursors; there are, however, some peculiarities associated with these techniques which may raise questions, especially from persons who are not acquainted with the details of ionospheric studies. The first misunderstanding results from the complexity of spatial and temporal dependence of ionospheric precursors. This problem is explained in Pulinets et al. (2004a), and here we only shortly depict it. According to theoretical calculations (Pulinets et al. 2000) the deviation of the electron concentration in the ionosphere may be positive or negative depending on the direction of the anomalous electric field. This results in the complex shape of the temporal variations of the critical frequency before earthquakes registered by ionosondes situated within the area of the earthquake preparation (Chuo et al. 2001). The shape of a precursor depends not only on the process itself (seismo-ionospheric coupling) but on the relative position of the impending earthquake epicenter and ionosondes as well (Pulinets et al. 2004a). Taking into account that GPS TEC records have very high correlation with ionosonde critical frequency records (Liu et al. 2004) this conclusion relates to the GPS TEC single station measurements too.

Another scenario can be observed from the topside sounding data. It is possible using the records of satellite consecutive orbits to make an LT-map of the ionosphere over the earthquake preparation zone (Pulinets and Legen'ka 2003). This technique gives an opportunity to obtain a snapshot of the ionosphere revealing real distribution of electron density for a given local time. It is one of the great advantages in using a satellite as it gives reading prior to ground based measurements. However, the increasing number of GPS receivers all over the world opens up the possibility of making a GPS map of the ionosphere, including periods of earthquake preparation. This technique has an advantage over topside sounding, because it permits the production of time-lapse maps, showing ionosphere dynamics in real time (Liu et al. 2001, 2002). An example of a GPS TEC map demonstrating precursors before the Colima earthquake in Mexico (21.01.2003, M 7.8) is shown in Fig. 5. The map is built to correspond to the TEC peak registered at 1010 LT on January 18 ( 3 days before earthquake) which one can observe in the Fig. 4 of the GPS TEC record for the Colima station. The anomalous increase of the electron density is observed exactly over the epicentral area (Pulinets et al. 2003). 

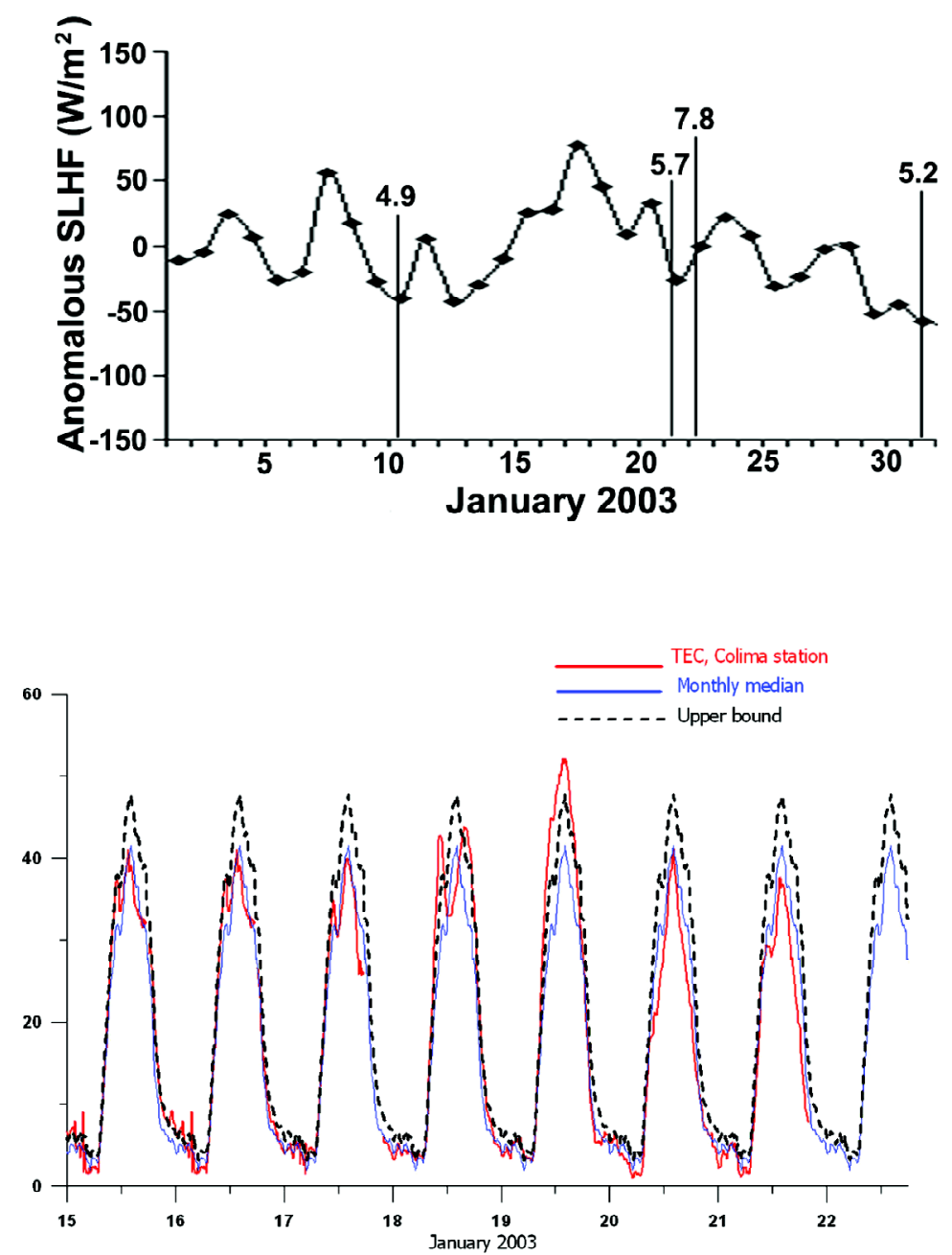

Fig. 4. (a) Anomalous SLHF registered in Colima vicinity, Mexico in January 2003, (b) Vertical TEC registered by Colima GPS receiver, bold line actual measurements, thin line - monthly median, dashed line - upper bound $+2 \sigma$ from the monthly median.

At the same time GPS technology has similar limitations as it is applicable only for land based registration. If an epicenter is situated in the ocean which is the case for the most of Pacific coast earthquakes in Mexico, a large probability of missing the precursors exists. This situation is aggravated by the fact that precursors are generally observed over geomagnetic field lines in an equatorial direction and not exactly over the epicentral area. In the case of Mexico the coastal configuration raises the probability of missing precursors due to a shift 
over open ocean where GPS receivers cannot be placed.

More also needs to be said regarding recent developments of occultation technology or GPS MET technology. Occultation profiles obtained by one satellite are distributed chaotically in space and time and cannot completely fit the requirements of ionospheric precursor tracking. This type of tracking requires profiles be obtained at least once a day at the same local time (as is the case in topside sounding) in the same geometric configuration, or temporal evolution of precursors should be tracked as in the case of ground based ionosonde or GPS receivers. A new perspective, however, will open up when the multisatellite constellations are created, the COSMIC project, to provide continuous monitoring of the same place in the same configuration.

As a conclusion it needs to be stated that for high confidence in results all three techniques should be used simultaneously. Taking into account the encouraging results obtained using the topside sounding technique, the launch of satellites with topside sounders onboard is an urgent requirement of short-term earthquake prediction.

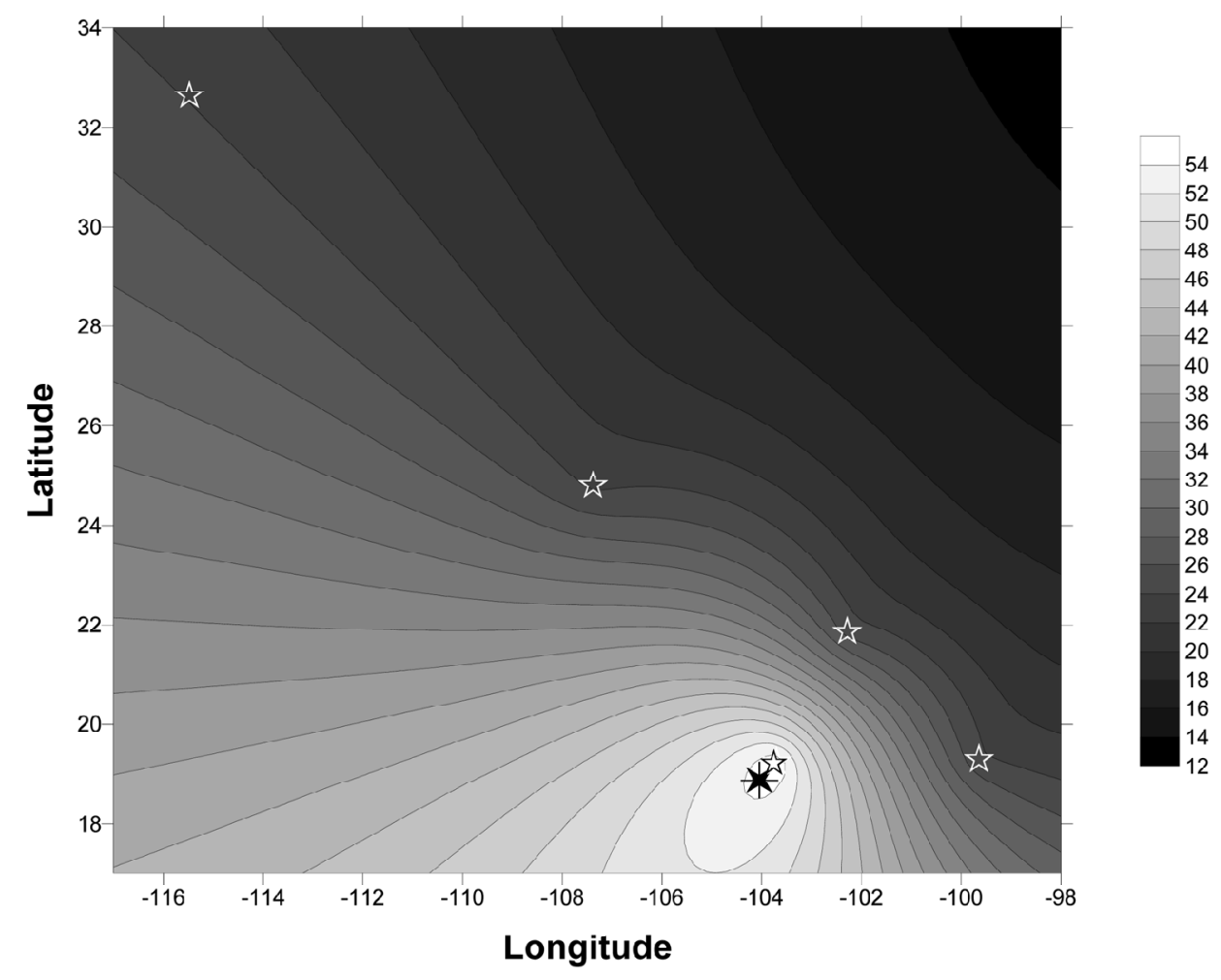

Fig. 5. Map of the vertical TEC deviation (delta TEC) derived from the INEGI network of continuous GPS receivers for the 1010 LT on 18 January 2003. $\_$- GPS receivers positions, $*$ - earthquake epicenter position. 


\section{DEVELOPMENT OF PRACTICAL APPLICATIONS USING IONOSPHERIC PRECURSORS}

The present state of our understanding of ionospheric precursor properties has reached a level such that we can answer the when, where and how strong questions of short term prediction. Of course, the proposed techniques have limitations, but we are at least aware of the limitations and precision of each method.

For the time in main shock prediction two techniques can be reasonably proposed. The first one is the so called "precursor mask" technique (Pulinets et al. 2002b) where statistically determined precursors behavior in coordinates "days before the shock" - "local time" for the given area. It requires historical ionospheric data processing which allows for a statistical pattern to be formed for any given area. Another important factor is the more or less fixed relative position of the ionosonde (or GPS receiver) and an earthquake's epicentral area. The other technique described in Gaivoronskaya and Pulinets (2003) has an advantage over the first because it doesn't require historical data processing, and does not depend on the relative positions of the ionosonde and earthquake epicenter. For this proposed technique it is necessary to have two ionosondes (or GPS receivers). One of the stations should be inside the earthquake preparation zone, and the other outside of it. The second station shouldn't be sufficiently far $(\sim 500-700 \mathrm{~km})$ from the first one to ensure high correlation between the ionospheric records. The daily cross-correlation coefficient (3) for the two stations should be calculated where the hourly values of the critical frequencies $f o F 2$ are used. The same technique can be used for GPS TEC records using data from two receivers selected by the same criteria as the ionospheric stations (Pulinets et al. 2004b). The summation index in this case will be different depending on the GPS data sampling interval,

$$
C=\frac{\sum_{i=0, k}\left(f_{1, i}-a f_{1}\right)\left(f_{2, i}-a f_{2}\right)}{k\left(\sigma_{1} \sigma_{2}\right)} .
$$

Here indices 1 and 2 correspond to the first and second ionospheric stations, $f=f o F 2$ (hourly values of the critical frequency scaled from the ionograms), $k=23$ and $a f$ and $\sigma$ are determined by the following expressions:

$$
\begin{gathered}
a f=\frac{\sum_{i=0, k} f_{i}}{k+1}, \\
\sigma^{2}=\frac{\sum_{i=0, k}\left(f_{i}-a f\right)^{2}}{k},
\end{gathered}
$$


$a f$ - is a daily mean value of the critical frequency, $\sigma$ - the standard deviation.

The cunning of the proposed technique lies in the fact that all ionospheric variations caused by solar and geomagnetic activity will be registered almost identically at both stations which will give a high correlation coefficient value (usually close to 0.9 ) even during strong geomagnetic disturbances (Pulinets et al. 2004c). The variations caused by seismic activity will be "felt" better by the station inside the earthquake preparation zone than by the station outside of it because of process locality. It will cause a sharp drop in the correlation coefficient. Statistically this drop happens within a time interval from 7 to 1 day in advance of the main seismic shock which is close to the value determined by other statistical processing (Chen et al. 1999; Liu et al. 2004) where an interval of 5 days before a seismic shock was determined as a most probable value for ionospheric precursors of earthquakes in the Taiwan area. Figure 6 demonstrates the cross-correlation coefficients calculated for two pairs of GPS receivers around the time of the Colima earthquake of January 21, 2003. Colima and Toluca receivers are closer to the epicenter. The Colima receiver is practically in the epicenter, and Toluca receiver is to the east of it by $\sim 300 \mathrm{~km}$. The Aguascalients receiver is $400 \mathrm{~km}$ to the north of the epicenter. One can see a drop in the correlation coefficient 5 days before the seismic shock in both panels, and during the day of the earthquake (in the right panel). Data from the Colima station are broken due to damage and a cut in electricity in Colima after the seismic shock.

So for testing of the proposed technique the warning period ought be established equal to 7 days after the appearance of a drop in the correlation coefficient. It gives precision of the shock time determination at $5-7$ days.

An impending earthquake's epicenter coordinates can be determined from ionospheric mapping accomplished by the topside sounding technique or by the relatively dense network of GPS receivers. From Fig. 5 one can see that the maximum ionospheric anomaly appears very close to the epicenter. Topside sounding data demonstrate that an ionospheric anomaly can drift within the period of the earthquake preparation of 5 days before the seismic shock (Pulinets and Legen'ka 2003) and can shift from the vertical epicenter position up to $10^{\circ}$ in latitude and longitude. This value determines the proposed technique's precision but it can be improved by statistical processing of data and taking into account regional peculiarities.

The impending earthquake magnitude can be determined from ionospheric mapping using the Dobrovolsky formula (1) if one considers the size of the ionospheric anomaly to be the same as the size earthquake preparation zone. Such an estimation is demonstrated in Fig. 7 where a critical frequency deviation as a function of latitude is shown for the ionospheric precursor registered by Intercosmos-19 satellite before the Irpinia earthquake of November 23, 1980. From Fig. 7 one can estimate the size of the modified area as $\sim 1800 \mathrm{~km}$, which gives the radius $\sim 900 \mathrm{~km}$. From (1) it is possible to estimate the magnitude: $M=[\log (900)] / 0.43=6.9$. It is exactly the magnitude of the Irpinia earthquake. Here, of course the satellite picture should correspond appropriately to the size of the area determined in the maximum phase of the ionospheric irregularity development, and conventions need to be established as to at what level to determine deviation, etc. Our task now is not to elaborate the exact procedure, but only 
Aguascalientes vs Toluca

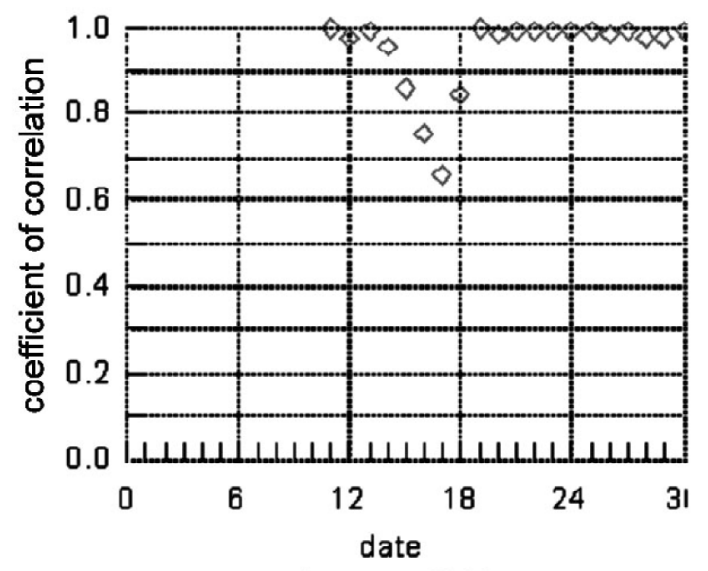

January, 2003
Colima vs Aguascalientes

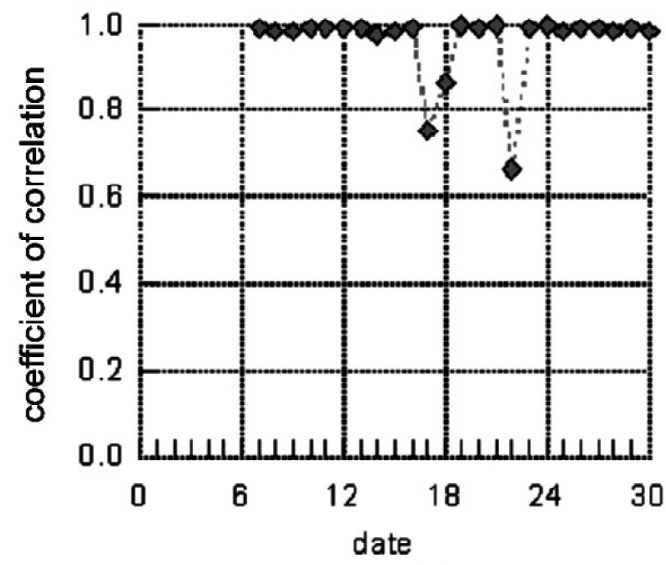

January. 2003

Fig. 6. Daily cross-correlation coefficient for vertical TEC derived from data of Colima, Toluca and Aguascalientes receivers for the period around the time of Colima earthquake. Left panel - correlation coefficient between Aguascalients and Toluca stations, Right panel - correlation coefficient between Colima and Aguascalientes stations.

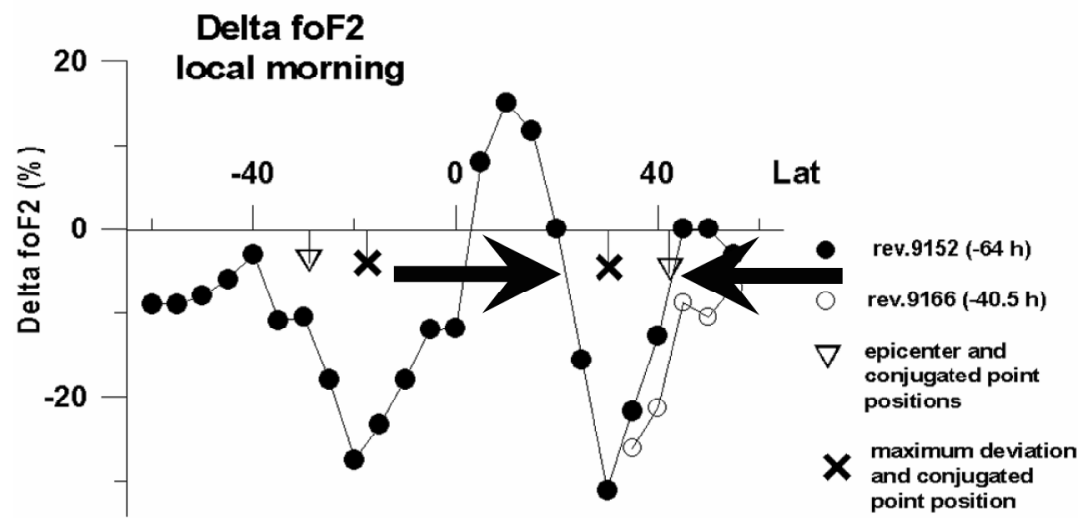

Fig. 7. Latitudinal cross-section of the critical frequency deviation derived from the topside ionograms of Intercosmos-19 satellite. Bold arrows show the size of the modified area of the ionosphere close to the epicenter latitude. 
to indicate the direction in which we can obtain this procedure.

\section{CONCLUSION}

The present paper accumulates recent advances in understanding of the physical mechanism of seismo-ionospheric coupling and some practical applications developed recently for short-term earthquake prediction using ionospheric precursors of earthquakes. Special attention is attracted to the connection between thermal anomalies and latent surface heat flux variations associated with the process of earthquake preparation and the presented model of seismo-ionospheric coupling. The most probable connection is provided by plasma-chemical processes in the troposphere that involve latent heat and water molecule attachment to ions produced by radon ionization. The model explains the interconnection of different electromagnetic precursors of earthquakes and build a precursor hierarchy. As presented the concept of an earthquake preparation zone joins geophysical and geochemical precursors with ionospheric precursors of earthquakes showing that the latter belong to the same family and should be regarded by seismology equally. Advantages and disadvantages are regarded concerning different techniques of ionospheric monitoring in relation to ionospheric precursor registration. The main and probably most important conclusion lies in the fact that the level of our present knowledge of ionospheric precursors of earthquake permits us to use them already in shortterm earthquake prediction at least in the testing regime demonstrated in the last paragraph.

Acknowledgements This work was supported by the grants of PAPIIT IN 126002, and CONACYT 40858-F. Author would like to thank the head of iSTEP project prof. Y. B.Tsai and the head of the subproject 4 prof. J.Y.Liu for their support of my activity in Taiwan by providing the ionospheric and seismic data, financial support in several stays in Taiwan, and fruitful discussions and cooperation within the frame of iSTEP project.

\section{REFERENCES}

Antselevich, M. G., 1971: The influence of Tashkent earthquake on the Earth's magnetic field and the ionosphere. In: Tashkent earthquake 26 April 1966, FAN Publ. Tashkent, 187-188p.

Bardakov, V. M., B. O. Vugmeister, A. V. Petrov, and A. A. Chramtsov, 2004: Excitation of VLF-signals under earthquake preparation process, Preprint, Irkutsk State Technical University, Irkutsk, 16p.

Biagi, P. F., A. Ermini, and S. P. Kingsley, 2001: Disturbances in LF radiosignals and the Umbria-Marche (Italy) seismic sequence in 1997-1998. Phys. Chem. Earth., 26, 755759.

Calais, E., and J. B. Minster, 1995: GPS detection of ionospheric TEC perturbations following the January 17, 1994, Northridge Earthquake. Geophys. Res. Lett., 22, 1045-1048. 
Chen, Y. I., J. Y. Chuo, J. Y. Liu, and S. A. Pulinets, 1999: Statistical study of ionospheric precursors of strong earthquakes at Taiwan area, XXVI URSI General Assembly, Toronto, 13-21 Aug. 1999, Abs., 745p.

Chmyrev, V. M., N. V. Isaev, O. N. Serebryakova, V. M. Sorokin, and Y. P. Sobolev, 1997: Small-scale plasma inhomogeneities and correlated ELF emissions in the ionosphere over an earthquake region. J. Atmos. Solar-Terr. Phys., 59, 967-974.

Chuo, Y. J., Y. I. Chen, J. Y. Liu, and S. A. Pulinets, 2001: Ionospheric $f o F 2$ variations prior to strong earthquakes in Taiwan area. Advances in Space Res., 27, 1305-1310.

Datchenko, E. A., V. I. Ulomov, and C. P. Chernyshova, 1972: Electron density anomalies as the possible precursor of Tashkent earthquake. Dokl. Uzbek. Acad. Sci., No. 12, 30-32.

Davies, J. B., and C. B. Archambeau, 1998: Modeling of atmospheric and ionospheric disturbances from shallow seismic sources. Phys. Earth Planet. Inter., 105, 183-199.

Davies, K., and D. M. Baker, 1965: Ionospheric effects observed around the time of the Alaskan earthquake of March 28 1964. J. Geophys. Res., 70, 2251-2253.

Dey, S., and R. P. Singh, 2003: Surface latent heat flux as an earthquake precursor.Nat. Haz. Earth Syst. Sci., 3, 749-755.

Dobrovolsky, I. R., S. I. Zubkov, and V. I. Myachkin, 1979: Estimation of the size of earthquake preparation zones. Pageoph., 117, 1025-1044.

Dobrovolsky, I. R., N. I. Gershenzon, and M. B. Gokhberg, 1989: Theory of electrokinetic effects occurring at the final stage in the preparation of a tectonic earthquake. Phys. Earth Planet. Inter., 57, 144-156.

Ducic, V., J. Artru, M. Murakami, and P. Lognonne, 2003: Ionospheric remote sensing of the Denali Earthquake rayleigh surface waves. AGU 2003 Fall Meeting S12A-0370.

Fleischer, R. I., 1981: Dislocation model for radon response to distance earthquakes. Geophys. Res. Let., 8, 477-480.

Gaivoronskaya, T. V., 1991: The seismic activity effects on the ionosphere. The Review, Preprint IZMIRAN No.36(983) Moscow, 25 p.

Gaivoronskaya, T. V., S. A. Pulinets, 2002: Analysis of F2-layer variability in the areas of seismic activity, Preprint IZMIRAN No. 2(1145) Moscow, 20 p.

Galper, A. M., S. V. Koldashov, and S. A. Voronov, 1995: High energy particle flux variations as earthquake predictors. Adv. Space Res., 15, 131-134.

Gokhberg, M. B., V. A. Pilipenko, and O. A. Pokhotelov, 1983: Seismic precursors in the ionosphere. Izvestiya Earth Physics, 19, 762-765.

Gokhberg, M. B., V. A. Morgounov, and O. A. Pokhotelov, 1995: Earthquake Prediction. Seismo-electromagnetic phenomena. Gordon and Breach Science Publishers, Amsterdam.

Gufeld, I. L., A. A. Rozhnoy, S. N. Tyumentsev, S. V. Sherstyuk, and V. S. Yampolsky, 1992: Radio wave field disturbances prior to Rudbar and Rachinsk earthquakes. Izvestiya. Earth Physics, 28, 267-270.

Hao, J., T. Tang, and D. Li, 2000: Progress in the research of atmospheric electric field anomaly as an index for short-impending prediction of earthquakes.J. Earthquake Pred. Res., 8 , 241-255. 
Hattori, K., Y. Akinaga, M. Hayakawa, K. Yumoto, T. Nagao, and S. Uyeda, 2002: ULF magnetic anomaly preceding the 1997 Kagoshima Earthquakes. In: M. Hayakawa and O. A. Molchanov (Eds.), Seismo-Electromagnetics: Lithosphere-Atmosphere-Ionosphere Coupling, TERRAPUB, Tokyo, 19-28.

Hegai, V. V., V. P. Kim, and L. I. Nikiforova, 1997: A possible generation mechanism of acoustic-gravity waves in the ionosphere before strong earthquakes. $J$. Earthquake Predict. Res., 6, 584-589.

Horanyi, M., and C. K. Goertz, 1990: Coagulation of dust particles in a plasma.Astrophys. J., 361, 155-161.

Ismaguilov, V. S., Y. A. Kopytenko, K. Hattori, P. M. Voronov, O. A. Molchanov, and M. Hayakawa, 2001: ULF magnetic emissions connected with under sea bottom earthquakes. Nat. Haz. Earth Syst. Sci., 1, 23-31.

Jianguo, H., 1989: Near earth surface anomalies of the atmospheric electric field and earthquakes. Acta Seismol. Sin., 2, 289-298.

Kikuchi, H., 2001: Electrodynamics in dusty and dirty plasmas, Kluwer Academic Publishers.

Kim, V. P., V. V. Hegai, and P. V. Illich-Svitych, 1994: On the possibility of a metallic ion layer forming in the E-Region of the night midlatitude ionosphere before great earthquakes. Geomagn. and Aeronomy., 33, 658-662.

Kim, V. P., and V. V. Hegai, 1997: On possible changes in the midlatitude upper ionosphere before strong earthquakes. J. Earthq. Predict. Res., 6, 275-280.

Kim, V. P., S. A. Pulinets, and V. V. Hegai, 2002: Theoretical model of possible disturbances in the nighttime mid-latitude ionospheric D-region over an area of strong earthquake preparation. Radiophys. Quantum Electronics, 45, 262-268.

Kossobokov, V. G., V. I. Keilis-Borok, D. L. Turcotte, and B. D. Malamud, 2000: Implications of a statistical physics approach for earthquake hazard assessment and forecasting. Pure Appl. Geophys., 157, 2323-2349.

Krasikov, N. N., 2001: The characteristic of electricity in lower layers of the atmosphere, Doklady. Earth Sci., 377, 263-265.

Krider, E. P. and R. W. Roble, (Eds.), 1986: The Earth's Electrical Environment. National Academy Press, Washington D.C.

Kushida, Y. and R. Kushida, 2002: Possibility of earthquake forecast by radio observations in the VHF Band. Jo. Atmos. Electricity, 22, 239-255.

Larkina, V. I., V. V. Migulin, O. A. Molchanov, I. P. Khar'kov, A. S. Inchin, and V. B. Schvetcova, 1989: Some statistical results on very low frequency radiowave emissions in the upper ionosphere over earthquake zones. Phys.Earth Planet.Inter., 57, 100-109.

Liperovsky, V. A., O. A. Alimov, S. A. Shalimov, M. B. Gokhberg, R. H. Liperovskaya, and A. Saidshoev, 1990: Ionosphere F-region studies before earthquakes. Izvestiya Ussr Acad. Sci. Physics Solid Earth, 12, 77-86.

Liperovsky, V. A., O. A. Pokhotelov, and S. A. Shalimov, 1992: Ionospheric precursors of the earthquakes. Nauka, Moscow, 304 p (in Russian).

Liperovsky, V. A., O. A. Pokhotelov, E. V. Liperovskaya, M. Parrot, C. -V. Meister, and O. A. Alimov, 2000: Modification of sporadic E-layers caused by seismic activity. Surveys in Geophys., 21, 449-486. 
Liu, J. Y., Y. I. Chen, Y. J. Chuo, and H. F. Tsai, 2001: Variations of ionospheric total content during the Chi-Chi earthquake. Geophys. Res. Lett., 28, 1381-1386.

Liu, J. Y., Y. J. Chuo, S. A. Pulinets, H. F. Tsai, X. Zeng, 2002: A study on the TEC perturbations prior to the Rei-Li, Chi-Chi and Chia-Yi earthquakes. In: Hayakawa M. and O. A. Molchanov (Eds.), Seismo-Electromagnetics: Lithosphere-Atmosphere-Ionosphere Coupling, TERRAPUB, Tokyo, 297-301p.

Liu, J. Y., Y. J. Chuo, S. J. Shan, Y. B. Tsai, S. A. Pulinets, and S. B. Yu, 2004: Pre-earthquake ionospheric anomalies monitored by GPS TEC. An. Geophys., 22, 1585-1593.

Mareev, E. A., D. I. Iudin, and O. A. Molchanov, 2002: Mosaic source of internal gravity waves associated with seismic activity. In: Hayakawa M. and O. A. Molchanov (Eds.), Seismo-Electromagnetics: Lithosphere-Atmosphere-Ionosphere Coupling, TERRAPUB, Tokyo, 335-342p.

McCormick, R. J., C. J. Rodger, and N. R. Thomson, 2002: Reconsidering the effectiveness of quasi-static thunderstorm electric fields for whistler duct formation.J Geophys. Res. ,107, 1396, doi: 10.1029/2001 JA 009219.

Mjachkin, V., W. Brace, G. Sobolev, and J. Dietrich, 1975: Two models of earthquake forerunners. Pageoph., 113, 169-181.

Moore, G. W., 1964: Magnetic disturbances preceding the 1964 Alaska Earthquake.Nature, 203, 508-512.

Nagao, T., Y. Enomoto, Y. Fujinawa, M. Hata, M. Hayakawa, Q. Huang, J. Izutsu, Y. Kushida, K. Maeda, K. Oike, S. Uyeda, and T. Yoshino, 2002: Electromagnetic anomalies associated with 1995 KOBE earthquake. J. Geodynamics, 33, 401-411.

Nikiforova, N. N., and S. Michnowski, 1995: Atmospheric electric field anomalies analysis during great Carpatian Earthquake at Polish Observatory Swider. IUGG XXI General Assem. Abst., Boulder, Colo., VA11D-16.

Ondoh, T., and M. Hayakawa, 1999: Anomalous Occurrence of Sporadic E-layers before the Hyogoken-Nanbu Earthquake, M 7.2 of January 17, 1995. In: Hayakawa M. (Ed.), Atmospheric and Ionospheric Electromagnetic Phenomena Associated with Earthquakes. TERRAPUB, Tokyo, 629-640p.

Parrot, M., J. Achache, J. J. Berthelier, E. Blanc, A. Deschamps, F. Lefeuvre, M. Menvielle, J. L. Plantet, P. Tarits, and J. P. Villain, 1993: High frequency seismo-electromagnetic effects. Phys. of Earth and Planet. Inter., 77, 65-83.

Pulinets, S. A., and A. D. Legen'ka, 1994: Alekseev V.A., Pre-earthquakes effects and their possible mechanisms. In: Dusty and Dirty Plasmas, Noise and Chaos in Space and in the Laboratory. Plenum Publishing, New York, 545-557p.

Pulinets, S. A., V. V. Khegai, K. A. Boyarchuk, and A. M. Lomonosov, 1998: Atmospheric electric field as a source of ionospheric variability. Physics-Uspekhi, 41, 515-522.

Pulinets, S. A., K. A. Boyarchuk, V. V. Khegai, V. P. Kim, and A. M. Lomonosov, 2000: Quasielectrostatic model of atmosphere-thermosphere-ionosphere coupling.Adv. Space Res., 26, 1209-121.

Pulinets, S. A., K. A. Boyarchuk, V. V. Hegai, and A. V. Karelin, 2002a: Conception and model of seismo-ionosphere-magnetosphere coupling. In: Hayakawa M. and O. A. Molchanov (Eds.), Seismo-Electromagnetics: Lithosphere-Atmosphere-Ionosphere Coupling, TERRAPUB, Tokyo, 353-361p. 
Pulinets, S. A., K. A. Boyarchuk, A. M. Lomonosov, V. V. Khegai, and J. Y. Liu, 2002b: Ionospheric Precursors to Earthquakes: A Preliminary Analysis of the foF2 Critical Frequencies at Chung-Li Ground-Based Station for Vertical Sounding of the Ionosphere (Taiwan Island). Geomagnetism and Aeronomy, 42, 508-513.

Pulinets, S. A., and A. D. Legen'ka, 2003: Spatial-temporal characteristics of the large scale disturbances of electron concentration observed in the F-region of the ionosphere before strong earthquakes. Cosmic Res., 41, 221-229.

Pulinets, S. A., A. Leyva Contreras, G. Bisiacchi, L. Ciraolo, and R. Singh, 2003: Ionospheric and thermal precursors of Colima earthquake of 22 January 2003. Ann. Meeting Mexican Geophysical Union. GEOS 23, 170.

Pulinets, S. A., and K. A Boyarchuk., 2004: Ionospheric Precursors of Earthquakes, Springer Verlag Publ.

Pulinets, S. A., J. Y. Liu, and I. A. Safronova, 2004a: Interpretation of a statistical analysis of variations in the $f o F 2$ critical frequency before earthquakes based on data from ChungLi ionospheric station (Taiwan). Geomagn. Aeronom., 44, 102-106.

Pulinets, S. A., T. B. Gaivoronska, and A. Leyva Contreras, 2004b: Correlation analysis technique revealing ionospheric precursors of earthquakes, EGU General Assembly, Nice, France., Geophys. Res. Abs., Vol. 6, 01055.

Pulinets, S. A., A. Leyva Contreras, T. B. Gaivoronska, and I. A. Safronova, 2004c: Ionospheric day-to-day variability and spatial-temporal correlation, IRI Task Force Activity Workshop, ICTP, Trieste, Italy.

Pulinets, S., A. Karelin, K. Boyarchuk, A. Leyva, D. Ouzounov, L. Ciraolo, G. Bisiacchi, R. Singh, M. Dunajecka, 2004d: Thermal, atmospheric and ionospheric anomalies around the time of Colima earthquake 21.01.03 M=7.8, Mexico, submitted to Pure and Applied Geophys..

Rulenko, O. P., 2000: Operative precursors of earthquakes in the near-ground atmosphere electricity. Vulcanology and Seismology, 4, 57-68.

Scholz, C. H., L. R. Sykes, and Y. P. Aggarwal, 1973: Earthquake prediction: A physical basis. Science, 181, 803-809.

Sedunov, Y. S., O. A. Volnovitskii, N. N. Petrov, R. G. Reitenbakh, V. I. Smirnov, and A. A. Chernikov, 1997: Atmosphere, Handbook (Reference data and Models), Leningrad, Gidrometeoizdat.

Shklyar, D. R., and I. Nagano, 1998: On VLF wave scattering in plasma with density irregularities. J. Geophys. Res., 103, 29515-29526.

Sorokin, V. M., V. M. Chmyrev, and M. Hayakawa, 2000: The formation of ionospheremagnetosphere ducts over the seismic zone. Planet. Space Sci., 48, 175-180.

Toutain, J. P., and J. C. Baubron, 1998: Gas geochemistry and seismotectonics: a review. Tectonophys., 304, 1-27.

Tramutoli, V., G. Di Bello, N. Pergola, and S. Piscitelli, 2001: Robust satellite techniques for remote sensing of seismically active areas. Annali de Geofisica, 44, 295-312.

Tronin, A. A., 2002: Atmosphere-lithosphere coupling. Thermal anomalies on the Earth surface in seismic processes. In: Hayakawa M. and O. A. Molchanov (Eds.), SeismoElectromagnetics: Lithosphere-Atmosphere - Ionosphere Coupling, TERRAPUB, Tokyo, 173-176p. 
Tronin, A. A., M. Hayakawa, and O. A. Molchanov, 2002: Thermal IR satellite data application for earthquake research in Japan and China. J Geodyn., 33, 519-534.

Vershinin, E. F., A. V. Buzevich, K. Yumoto, K. Saita, and Y. Tanaka, 1999: Correlations of seismic activity with electromagnetic emissions and variations in Kamchatka region. In: Hayakawa M. (Ed.), Atmospheric and Ionospheric Electromagnetic Phenomena Associated with Earthquakes, TERRAPUB, Tokyo, 513-517p.

Voitov, G. I., and I. P. Dobrovolsky, 1994: Chemical and isotopic-carbon instabilities of the native gas flows in seismically active regions. Izvestiya Earth Science, 3, 20-31.

Zafrir, H., B. Ginzbutg, I. Hrvoic, and B. Shirman, 2003: Ultra sensitive monitoring of the geomagnetic field combined with radon emanation as a tool for studying earthquake related phenomena. AGU 2003 Fall Meeting, T51E-0206. 